\title{
Preface to the special issue for the proceedings of the Fourth China-Japan-Korea Conference on Numerical Mathematics
}

\author{
Hisashi Okamoto · Dongwoo Sheen · Zhong -Ci Shi
}

Published online: 9 October 2013

(C) The JJIAM Publishing Committee and Springer Japan 2013

The present issue of Japan Journal of Industrial and Applied Mathematics contains papers which were presented in the Fourth China-Japan-Korea Conference on Numerical Mathematics. The conference was held in Otsu city, Shiga Prefecture, Japan in August 25-28, 2012. Among many papers presented in the conference, the thirteen papers are selected and published in this issue.

We feel privileged to have organized this series of conferences, since the CJK conferences have injected stimuli in activities of numerical mathematics in these three countries: We firmly believe that the proceedings will help promote the cutting-edge expertise on numerical mathematics. Accordingly we are very happy as they are published in JJIAM, and we cordially thank its editors. The conference was a part of the Research Project "Emerging Applications of Highly Accurate Numerical Methods" of Research Institute for Mathematical Sciences, Kyoto University. The financial support from RIMS and the Global COE program, in which RIMS was participating, is highly acknowledged. Lastly it is our great pleasure to express our gratitude for the secretarial support from RIMS.

September 2013

H. Okamoto

D. Sheen

Z.-C.Shi

H. Okamoto $(\square)$

Research Institute for Mathematical Sciences, Kyoto University, Kyoto 606-8502, Japan

e-mail: okamoto@kurims.kyoto-u.ac.jp

D. Sheen

Department of Mathematics, Seoul National University, Seoul, 151-747, Korea

e-mail: sheen@snu.ac.kr

Z.-C. Shi

Institute of Computational Mathematics, Chinese Academy of Science,

P.O. Box 2719, Beijing 100190, China 